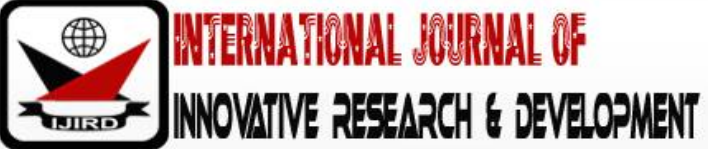

ISSN 2278 - 0211 (Online)

\section{Tourism as Indices for Sustainable Development in Cross River State, Nigeria}

\author{
Dr. Otukpa, Joseph 0. \\ Lecturer, Department of Sociology, Management and Social Sciences \\ Arthur Jarvis University, Nigeria \\ Beauty Usoroh Kenneth \\ Researcher, Department of Sociology, University of Calabar, Nigeria \\ Dr. Ekong I. David \\ District Police Officer, Akim Police Division, Calabar, Nigeria
}

\begin{abstract}
:
The main focus of this study was to examine tourism as indices for sustainable development of the people of Cross River State, Nigeria. Specifically, the study examined the extent to which tourism contributes to improved social status, and increased educational opportunities of the people of Cross River State. These two variables formed the objectives and hypotheses used for the study. Relevant literatures were reviewed while Endogenous Development Model constituted the theoretical framework for the study. The research design employed was a survey design, with a sample of 400 respondents selected using the Taro Yamene's (1967) sample size determination technique. Multi-stage sampling techniques were used to select respondents from the delineated clusters using an 18-item questionnaire as an instrument. Demographic data were presented using simple percentages, while hypotheses were tested with two statistical tools. Hypotheses one was analyzed using the one-way analysis of variance (ANOVA) while hypothesis two used linear regression statistical method all at 0.05 level of significance. The study found out that there is a significant relationship between tourism and improved social status as well as increased educational opportunities for sustainable development of the people of Cross River State, Nigeria. The study concluded that in spite of the high recognition of the state as the tourist base of the nation, the multiplier effect on individuals, and sustainable development is still not very noticeable. This is also the case with the internally generated revenue of the state, high rate of youth unemployment, youth restiveness, poor road network and poor manpower development. From the study, it was therefore recommended that the Government of Cross River state should intensify efforts in expanding the tourism sector to other areas in dire need of tourism potential such as cultural tourism. (Word count: 306)
\end{abstract}

Keywords: Tourism development, socio-economic well-being, stakeholders, diversification, sustainability, human capacity building

\section{Introduction}

Tourism translates to a sustainable development activity by residents for tourist expedition with the hope of improving human conditions and economic progress in their living standards. Tourism promotes social activities like travelling outside the usual environment by individuals for different purposes. It is seen as a primary set of social practices interconnected with all aspects of human daily living and touches people connection with others and places, (Dalat 2010; Ekwere 2010) respectively. Its role however has gone beyond mere integration of human development and settled on exemplifying human freedom, rights and sustainable development. In the area of economic activities, tourism is considered a major driver in sustainable development of many developed and developing countries of the world which serve as an alternative measure to diversification of a sustainable economy.

Tourism as a sector enhances the demand for transportation for the promotion of international tourism, telecommunication and other related services in the patronage of local products by tourists such as car hiring, food items, cultural artifacts, hotel accommodation, talent hunt and show case and other miscellaneous expenditure. Several scholars have identified tourism as a high-profile sector with a multi-dimensional nature and have great potentials in revamping an economy if keyed into by a nation.

The federal government of Nigeria having realized the significant benefits of this sector as a major channel for the diversification of the nation's economy from oil, called for a more radical approach to promote and exploit the tourism industry for sustainable development. Dalat, (2010) observed that, Nigeria economy could thrive if tourism is considered as one of the channels to enhance its economy base while still focusing on Agriculture and petroleum. 
In Cross River State, the sector has become an important channel of diversifying the economy of the state from oil industry which has significantly dominated other sectors for some decades. The State government had relied on the oil sector since 1967, until it was deprived of it by the Federal Government and handed over to the near-by Akwa Ibom State in 2008. Thus, it became necessary to shift to an alternative source of socio-economic development measure. Consequently, the Cross-River state Government has been consistent in developing tourism, through the establishment of many tourism sites in the state to help tap the enormous potentials from tourism to generate income, employment and educational opportunities in the state. We have witnessed the high level of investment made in the educational sector through establishment of schools including tertiary institutions, health sector, work and the power sector amongst others across the State. This development has led to increased educational opportunities.

Tourism as indices for sustainable development benefits the area endowed with tourism potentials through improving the social status of residence in the host communities, as well as increased access to educational opportunities. This study ascertained the practical influence in the area of human capacity building considering the height of investment from the time of its inception by the Government of Cross River State. Therefore, tourism and its impact on sustainable development of the people of Cross River State was the focus of the study.

\subsection{Statement of the Problem}

If a cursory look is taken across the state, a richly endowed state with a wide range of natural and cultural resources is acknowledged. The state has been from time of its creation in 1967, dependent on federal allocation; derivation fund from oil wells and internally generated revenue. These sources of revenue have been the basis for sustainable development of the state until the $10^{\text {th }}$ of October, 2002, the International Court of Justice at Hague in her judgment on Nigeria-Cameroon maritime boundary dispute, ceded part of the state which is oil rich Bakassi peninsula to Cameroon Republic and the eventual loss of State oil wells to Akwa Ibom State on the 14th of August, 2008 respectively. (Judgment, ICJ Reports, 2002). Since this period, the economy of the state has experienced serious setback because of its reliance on the oil sector. In order to probe up or diversify the state economy, the State Government identified tourism as a strategy to boost its economy base, thus Cross River State tourism bureau under the tourism bureau Act No. 6 of 2003 was established. To compliment this measure, successive administrations have contributed towards this drive to the detriment of other sectors of the economy evident in the establishment of tourism attraction sites across the three senatorial districts of the State. In spite of the huge contribution of tourism to the revenue base of the state, sustainable development of those in the tourism communities has not shown any significant improvement. This study therefore, seeks to examine Tourism and its contribution to sustainable development of the people of the state.

\subsection{Objectives of the Study}

The main objective of this study was to examine tourism and its contribution to sustainable development of the people of cross river state, Nigeria. The specific objectives were to:

- Examine the extent to which tourism influenced improved social status of the people of Cross River State.

- Determine the extent to which tourism relate to increased educational opportunities of the people of Cross River State.

- Identify problems that militate against tourism and sustainable development of the people of Cross River State and strategies that could be adopted in addressing them.

\subsection{Research Hypotheses}

The following hypotheses were tested in the study.

- There is no significant influence between tourism and improved social status of the people of Cross River State.

- There is no significant relationship between tourism and increased educational opportunities of the people Cross River State.

\section{Literature Review and Theoretical Framework}

\subsection{Tourism and Improved Social Status}

Once a community becomes a destination, the consequences of tourism will significantly influence the quality of life of the hosts (Wall \& Mathieson, 2006). Such consequences include, enhancing a common understanding and improving the social status of host community, increased population, higher prices of goods and services, traffic congestion, and several economic and employment- based effects (Allen et al., 1994; Ap, 1992; Getz, 1994). De Kadt (1979) observed that, there are three types of interaction and contact between host community members and tourists. The first is the goods brought in by tourists and the services given by host community members. The second is the sharing of facilities between tourists and local residents while the last is the cultural exchange at the point of contact between tourists and local residents.

Archer, et al (2005) further reiterated that tourist aids in the preservation of historic relies or ancient culture. The social significance as well as benefits derived from tourism is that, tourism helps host communities to maintain and sustain their traditional culture, increased intercultural communication and understanding, improved social welfare, quality of life, reciprocal culture of give and take, improved shopping and offer improved leisure opportunity.

As a structural event, tourism is a social event which creates an enabling environment for fun seekers (Tsundoda et al, 2009). The social relationship and interaction that occurs among tourists and local residents may affect tourists depending on the mode of reception by host community members to tourists which is often owed to the fact that, most 
tourists may not be abreast with the customs and tradition of the host residents. This effect may either be positive or most times negative depending on the situation experienced by host residents (Mathieson et al, 1982). Through association and interaction with tourists, residents may learn newer tongues that can add value to their culture and lifestyle which in turn leads to development.

From this interaction, there may be improvement in the lifestyles of the local people, behavioural modification and infrastructural development from the restructured facilities and usher in new educational opportunities such as scholarships, employment and income generation. In addition, this interaction, may also bring a significant improvement in other activities not formally tapped as tourism potentials such as entertainment, exhibitions etc. These will also improve other social events such as sports like, football competitions as well as dancing competitions to add colours to the period of event, preservation and conservation of traditional cultural heritage which will promote significant cultural rebirth of ancestral artifacts. Visitation by tourists in all tourism destinations often bring about cultural rebirth and development.

The impact of the tourism industry does significantly improve the sustainable development of host communities through the provision of health centres', motor able roads, good hospitals as well as the provision of other necessary infrastructure for the host community members (Umana, 2010).

\subsection{Tourism and Increased Educational Opportunities}

The sector shapes individuals' mental attitude through interaction with people from different linguistic background. Tourism development as an industry has the potentials to offer economic opportunity as well as educational development to local resident who actively participate in the sector (Udeme, 2010).

It offers travel tour to educators and other people for adventure purposes as most people often travel in badges to explore the countries natural and man-made resources and site seeing such as landmarks, landscapes, cultural events museums amongst others in appreciation of nature and other art works. It also offers opportunities for educational art travels, research expeditions, and the discovery world of technology and cultural studies of ancient cities.

It offers educational opportunities such as excursions to nomadic rural areas of the world within a specified time for the advancement of knowledge which in turn improves income earnings to host communities. In cross river state, the sector has developed her entrepreneurial skill, as the state was adjudged as the tourist base of the nation-Nigeria with a clean environment.

Education ranks high on tourism development and promotion campaigns, tackling lawlessness and ignorance regarding the importance of tourism as well as encouraging the citizen's pride in the culture and the beauty of their land. (Mocoamere, 2000). The Chief of Human Resource Development, WTO, Fayos-Sala confirms that there is a lack of quality in tourism education and training worldwide because it does not correspond well to the needs of employers. To become competitive in tourism, governments have to realize that human capital is just as important as financial capital. So, by improving education, we can create more jobs and equip new groups joining the industry with skills. Erdoardo in (World Tourism Organisation, 1998).

\section{Theoretical Framew ork}

\subsection{Endogenous Development Model}

The proponents of Endogenous Development Model are Bass and Brugger, Bryden, Friedman and Stuckey (1986). This theory states that the state of endogenous development is vested on the believe that sustainable development of marginalized societies can be harnessed collectively to a proper state that will be beneficial to them (Ray, 2000). Development is observed by this model to embrace not only good and efficient indications or not by good monetary measures but by the development of the social, political and ecological cultural, values as well as income earning that have a long-term effect on the host communities involved.

The major point of emphasis here is what can be done to support and assist disadvantaged groups to ensure an efficient economic growth (OECD, 1996).

The model has implications for the present study based on its belief that, development in Cross River State is not merely increasing the well-being of the people but the effective production of sustainable goods and services. Furthermore, it entails motivating the people through tourism activities to have control over their resources, environment, relationship as well as neighborhoods. This implies that through tourism, opportunities for income generation, employment/ job creation, increased educational opportunities and enhanced social status necessarily result in empowerment and capacity building which are key elements in the sustainable development process.

Based on the theory, tourism development is seen as a political, economic and institutional arrangement that can help in sustainable development. These arrangements comprise a rich service network that will promote good administration of the tourism sector for planning government prorammes aimed at motivating partners to have a good atmosphere for sustainable development. The outcome of this arrangement is improved social status, self-employment, income generation etc.

\subsection{Research Design}

This study employed the survey research design as well as quantitative and qualitative approaches to obtain data for analyses. The survey design was chosen because it helps to describe widespread variables with common characteristics needed for the study. Furthermore, the design was adopted for its reliability to help the researcher design a questionnaire and interview schedule for the collection of quantitative and qualitative data. This research design is chosen because it was most appropriate for a study interested in examining the impact of tourism on sustainable development 
translated into income generation, job creation, improved social status, increased educational opportunities and challenges. It involved the use of questionnaire as a research instrument which was administered on respondents to enable the researcher collect quantitative data. Also, the qualitative aspect was through focus group discussion (FGD) and in-depth interview. This in -depth interview method was carried out to obtain firsthand information to further strengthen data analysis.

\subsection{Population, Sample and Data collection}

Although the population of Cross River State according to the National Population Census (2006) is three million three hundred and thirty seven thousand five hundred and seventeen people $(3,337,517)$, the population, one million, eight hundred and eighty thousand, three hundred and ninety people $(1,880,390)$ of the selected Local Governments with tourism potentials was used as the base point. It is from this study's population, a sample of 400 respondents was drawn for the study. To get this sample size, the Taro Yamane's (1967) sample size determination technique (statistical Formula) was adopted. Data collection employed quantitative and qualitative approaches. The quantitative approach involves a structured questionnaire administered directly to the respondents by the researcher with the help of an assistant. The questionnaire was structured based on the variables developed under the objective and theoretical framework which were administered and retrieved with usable data.

The qualitative approach was focus group discussion (FGD) comprised of males and females aged between 24$60 \mathrm{yrs}$ of the active population who are mostly productive and always prepared to be engaged in tourism venture and indepth interview with a structured interview guide to collect information from stakeholders based on the variable under study. FGD required participants with at least a qualification of a First School Leaving Certificate (FSLC) with occupation as civil servant, farmer, politician, student and trader while in-depth interview (IDI) required the Secretary, Council of Chiefs, Yakurr local government area, the custodian of the policy framework of the festival to examine the impact of lebuku festival as an aspect of cultural tourism on sustainable development of the people.

On the same strength, the chairman of Cross River State Tourism Board was selected from his advantaged position in directing the overall management programme of the festival at the State level. He initiates all the planning process for the festival to take place and has records of past events at his disposal. These qualitative data gathered, compliment the quantitative data from the instrument.

\subsection{Testing of research hypotheses}

The testing was done hypothesis by hypothesis using relevant statistical technique to test each one at 0.05 level of significance. Descriptive statistics was used to answer the research questions, one-way analysis of variance (ANOVA) and Linear Regression analytical tools were used to test the hypotheses

\subsubsection{Hypothesis One}

There is no significant influence between tourism and improved Social Status of the people of Cross River State.

Independent Variable: Tourism

Dependent Variable: $\quad$ Improved social status

Statistical technique adopted: One-way analysis of variance (ANOVA)

\subsubsection{Hypothesis Two}

There is no significant relationship between tourism and increased educational opportunities of the people of Cross River State.

Independent Variable: $\quad$ Tourism

Dependent Variable: $\quad$ Increased educational opportunities

Statistical technique adopted: Linear regression.

\subsubsection{Sources of Data}

Two sources of data were explored for the study. These were: primary sources and secondary sources.

- Primary sources consisted of the first-hand information obtained from respondents in the process of field work. In this study, the questionnaire, personal interview and focus group discussion with the host communities made up the primary sources.

- The secondary sources involved research journals and existing literature of the works of other scholars related to the concept under study.

\subsubsection{Data Generation}

The data were generated from a 29-item instrument designed by the researcher. The instrument was divided into two sections. In section A, the researcher highlighted the purpose of the study and solicited for understanding of the respondents. The researcher, in section B requested the respondents to respond, in an honest manner, to all the items by placing a tick $(\sqrt{ })$ on any column of their choice particularly the ones that best satisfied them. 


\section{Data Presentation, Analysis and Discussion of Findings}

\subsection{Data Presentation}

Data in Table 1 showed the socio-demographic characteristics of respondents in respect to age revealed that majority 47.5 percent $(\mathrm{N}=190)$ were between $36-40$ yrs., respondents between the ages of 30-35yrs were 32.5 percent $(\mathrm{N}$ $=130)$, respondents in the group of those between the ages of 41 above yrs. were 20.5 percent $(\mathrm{N}=80)$. This implied that respondents 36-40 years were higher in percentage than other description. The distribution of respondents by educational qualification showed that majority of 48.3 percent $(\mathrm{N}=193)$ respondents had primary education, 32.3 percent $(\mathrm{N}=129)$ had the SSCE, while 19.5 percent $(\mathrm{N}=78)$ had tertiary education. This implies that amongst the study population, those with primary education were higher than other educational description. The spread of respondents in terms of occupational status shows that majority 37.5 per cent $(\mathrm{N}=150)$ were politicians, 30.0 percent $(\mathrm{N}=120)$ were trade/ business, 24.0 percent $(\mathrm{N}=96)$ were students; while 8.5 percent $(\mathrm{N}=34)$ were civil servants. This implied that majority of the respondent were politicians. The distribution of respondents by marital status showed that majority of the respondents 49.0 per cent $(\mathrm{N}=196)$ were single; 36.8 percent $(\mathrm{N}=147)$ were married while, 14.3 per cent of the respondents $(\mathrm{N}=57)$ were divorced/ separated. From this analysis, it is evidenced that majority of the respondents were singles followed by singles.

Table 2 shows the responses of respondents to the sub-scale on Tourism and improved social status with three options measurement scale raked as High, Moderate and Low to determine the extent to which tourism affect either positively or negatively, host communities of Cross River State in general. As presented in Table 4. 4, the first item sought to examine 'how is the standard of living of those employed? From the responses, majority of the respondent 155 (38.8) responded high, 137 (34.3) responded moderate while 108 (27.0) responded Low. Item 2 which examine to what extend is the family member benefiting from tourism development, the result showed that 192 (48.0) responded high, 150 (37.5) responded moderate while 58 (14.5) responded Low. Item 3 examine what is the development extent brought by tourism in the community? The result showed that 200 (50.0) responded high, 141 (35.5) responded moderate while 59 (14.8) responded Low. From the result, it implies that the social status of host communities is high among other committees of states or communities in the state or Nigeria.

Table 3 shows the responses of respondents to the sub-scale on Tourism and increased Educational opportunities, with four options of either "strongly agree, agree, undecided, disagree or strongly disagree". As presented in Table 4. 2 most of the respondents either strongly agreed or agreed to all the four items in this subscale. For item 1 which seeks to examine if the local host communities with tourism sites are ignorant of the importance of tourism, from the item, 111 (27.8) strongly agreed, 107 (26.8) agreed, 16 (4.0) did not decide, 88 (22.0) disagreed, while 78 (19.5) strongly disagreed. Item 2 which examine if Tourism has broadened the mental attitude of the local people, the result showed that 112 (28.0) strongly agreed, 95 (23.8) agreed, 27 (6.8) did not decide, 101 (25.3) disagreed while 65 (16.3) strongly disagreed. Item 3 examine If Tourism has caused people to travel for site seeing to experience nature and culture to enhanced their understanding, the result showed that 104 (26.0) strongly agreed, 122 (30.5) agreed, 15 (3.8) did not decide, 77 (19.3) disagreed while 82(20.5) strongly disagreed. Item 4 examine if Tourism development has brought about expansion of education and literacy of the people of CRS., result showed that 132 (33.0 strongly agreed, 106 (26.5) agreed, 39 (9.8) did not decide, 69 (17.3) disagreed while 54 (13.5) strongly disagreed. This implies that the independent variable (Tourism) affects the dependent variable (Educational opportunities).

Table 5 shows the responses of respondents to the sub-scale on Tourism and sustainable development, with five options of either "strongly agree, agree, undecided, disagree or strongly disagree". As presented in Table 4. 2 most of the respondents either strongly agreed or agreed to all the five items in this subscale. For item 1 which seeks to examine if We are empowered by tourism programmes, from the item, 111 (27.8) strongly agreed, 94 (23.5) agreed, 43 (10.8) did not decide, 72 (18.0) disagreed, while 80 (20.0) strongly disagreed. Item 2 which examine if There are enough micro credit facilities to boost the income status of rural dweller's, the result showed that 116 (29.0) strongly agreed, 143 (35.8) agreed, 12 (3.0) did not decide, 71 (17.8) disagreed while 58 (14.5) strongly disagreed. Item 3 examine If We have enough government approved skill acquisition due to tourist site in my community, the result showed that 117 (29.3) strongly agreed, 105 (26.3) agreed, 45 (11.3) did not decide, 77 (19.3) disagreed while 56 (14.0) strongly disagreed. Item 4 examine if Health care facilities are in good working condition in my community due to tourist sites, result showed that 106 (26.5) strongly agreed, 94 (23.5) agreed, 40 (10.0) did not decide, 87 (21.8) disagreed while 73 (18.3) strongly disagreed. Item 5 determine to what extent Tourism enhances job creation in a community. The result showed that 111 (27.8) strongly agreed, 119 (29.8) agreed, 18 (4.5) did not decide, 91 (22.8) disagreed while 61 (15.3) strongly disagreed. This implies that sustainable development of host communities is tied to tourism activities and programmes aimed at creating jobs, generate income to host communities, free medical services as major index of sustainable development. 


\begin{tabular}{|c|c|c|}
\hline Variables & Frequency & Percentage\% \\
\hline Sex distribution & Frequency & Percentages \\
\hline Male & 163 & 4.8 \\
\hline Female & 237 & 59.3 \\
\hline Total & 400 & 100 \\
\hline Age distribution & Frequency & Percentages \\
\hline $30-35$ years & 130 & 32.5 \\
\hline $36-40$ years & 190 & 47.5 \\
\hline 41 and above & 80 & 20.0 \\
\hline Total & 400 & 100 \\
\hline Level of education & Frequency & Percentages \\
\hline Primary education & 193 & 48.3 \\
\hline Secondary education & 129 & 32.3 \\
\hline Tertiary education & 78 & 19.5 \\
\hline Total & 400 & 100 \\
\hline Occupational attainment & Frequency & Percentages \\
\hline Civil servant & 34 & 8.5 \\
\hline Politician & 150 & 37.5 \\
\hline Trade/ business & 120 & 30.0 \\
\hline Students & 96 & 24.0 \\
\hline Total & 400 & 100 \\
\hline Marital status & Frequency & 49.0 \\
\hline Single & 196 & 36.8 \\
\hline Married & 147 & 14.3 \\
\hline Divorced/ divorcee & 57 & 100 \\
\hline Total & 400 & \\
\hline & & Percentages \\
\hline
\end{tabular}

Table 1: Demographic Information of Respondents Source: Field Survey 2019

\begin{tabular}{|c|c|c|c|c|}
\hline S/ N & Item & High & Moderate & Low \\
\hline 12 & How is the standard of living of those employed? & $155(38.8)$ & $137(34.3)$ & $108(27.0)$ \\
\hline 13 & $\begin{array}{c}\text { To what extend is the family members benefiting from } \\
\text { tourism }\end{array}$ & $192(48.0)$ & $150(37.5)$ & $58(14.5)$ \\
\hline 14 & $\begin{array}{c}\text { What is the development extend brought by tourism in } \\
\text { the community }\end{array}$ & $200(50.0)$ & $141(35.3)$ & $59(14.8)$ \\
\hline
\end{tabular}

Table 2: Tourism and Improved Social Status

Source: Field Survey 2019

\begin{tabular}{|c|c|c|c|c|c|c|}
\hline S/ N & ITEM & SA & A & UD & D & SD \\
\hline 15 & $\begin{array}{c}\text { The local host communities with tourism } \\
\text { sites are ignorant of the importance of } \\
\text { tourism }\end{array}$ & $111-27.8$ & $107(26.8)$ & $16(4.0)$ & $88(22.0)$ & $78(19.5)$ \\
\hline 16 & $\begin{array}{c}\text { Tourism has broadened the mental } \\
\text { attitude of the local people }\end{array}$ & $\begin{array}{c}112 \\
(28.0)\end{array}$ & $95(23.8)$ & $27(6.8)$ & $101(25.3)$ & $65(16.3)$ \\
\hline 17 & $\begin{array}{c}\text { Tourism has caused people to travel for } \\
\text { site seeing to experience nature and } \\
\text { culture to enhanced their understanding }\end{array}$ & $104(26.0)$ & $122(30.5)$ & $15(3.8)$ & $77(19.3)$ & $82(20.5)$ \\
\hline 18 & $\begin{array}{c}\text { Tourism has brought about expansion of } \\
\text { education and literacy of the people of } \\
\text { CRS. }\end{array}$ & $132(33.0)$ & $106(26.5)$ & $39(9.8)$ & $69(17.3)$ & $54(13.5)$ \\
\hline 19 & $\begin{array}{c}\text { We are empowered by tourism } \\
\text { programmes }\end{array}$ & $111(27.8)$ & $94(23.5)$ & $43(10.8)$ & $72(18.0)$ & $80(20.0)$ \\
\hline 20 & $\begin{array}{c}\text { There are enough micro credit facilities } \\
\text { to boost the income status of rural } \\
\text { dweller's }\end{array}$ & $116(29.0)$ & $143(35.8)$ & $12(3.0)$ & $71(17.8)$ & $58(14.5)$ \\
\hline 21 & $\begin{array}{c}\text { We have enough government approved } \\
\text { skill acquisition due to tourist site in my } \\
\text { community }\end{array}$ & $117(29.3)$ & $105(26.3)$ & $45(11.3)$ & $77(19.3)$ & $56(14.0)$ \\
\hline 22 & $\begin{array}{c}\text { Health care facilities are in good working } \\
\text { condition in my community due to } \\
\text { tourist sites }\end{array}$ & $106(26.5)$ & $94(23.5)$ & $40(10.0)$ & $87(21.8)$ & $73(18.3)$ \\
\hline 23 & $\begin{array}{c}\text { Tourism enhances job creation in my } \\
\text { community. }\end{array}$ & $111(27.8)$ & $119(29.8)$ & $18(4.5)$ & $91(22.8)$ & $61(15.3)$ \\
\hline
\end{tabular}

Table 3: Tourism and Sustainable Development

Source: Field Survey 2019 


\subsection{Data Analysis}

\subsubsection{Hypothesis One}

There is significant influence between tourism and improved social status of the people of Cross River State. The independent variable is Tourism, while the dependent variable is improved social status. To test the hypothesis, one-way analysis of variance was used to determine the significant influence of tourism on improved social status of host communities. The dependent variable- social status was disaggregated into three level of measurement (low status, moderate status and high status)

The result in the table above revealed that, there are three groups (low status, moderate status and high status), the calculated F ratio of 3.054 is statistically insignificant when compared with the critical F-ratio of 3.040 at 2, 381 degree of freedom. This means that the null hypothesis which states that, there is no significant influence between tourism and improved social status of the people of Cross River State is still retained till a post hoc test is performed. It then followed that since there is no significant group difference a Post hoc test was performed to check were the difference lies. The difference among the group varies, social status as disaggregated, respondents of the opinion that tourism enhances low social status differ significantly from respondents with moderate status to tourism and improved social status $(\mathrm{MD}=.109$; $\mathrm{p}<05$ ); while respondents access to tourism benefits to their community with moderate status did not differ significantly with respondents who were of the view that tourism highly improves social status of host communities $(\mathrm{MD}=-.793: \mathrm{p}$ $>$.05) similar result is seen between respondents with high status and low social status perception of their communities $(\mathrm{MD}=683 ; \mathrm{p}>\mathrm{.05})$. From this result, there is a significant difference between respondents' opinion about tourism and improved social status of host communities; hence the result of the post hoc test was statistically significant.

\subsubsection{Hypothesis Two}

There is no significant relationship between tourism and increased educational opportunities of the people Cross River State. In this hypothesis, the Independent variable is Tourism while the dependent variable is increased educational opportunities. To test the hypothesis, linear regression was employed to test the degree of effect of micro finance credit scheme on house hold income. Furthermore, the dependent variable was disaggregated into three- expansion of education literacy, shaping the mental attitude of the people, experience nature and culture. From the Decision rule: if $\mathrm{P}$ value is greater than 0.05 accept Ho reject $\mathrm{H}_{1}$

Results of regression analysis carried out reveal a P value of 0.087 with $\mathrm{df}(4,400)$ and an $F$ value 58.435 . This further followed by the $t$-value of 8.255 as against the critical $t$-value of 3.723 to determine the independent influence of tourism in the promotion of enhanced educational opportunities to the host communities. Furthermore, since $\mathrm{P}$ value is less than 0.05 , thus we reject the null hypothesis and accept the alternate hypothesis. This implies that there is significant relationship between tourism and increased educational opportunities of the p]Ieople Cross River State.

\begin{tabular}{|c|c|c|c|c|c|}
\hline & N & Mean & Std. Deviation & Std. Error \\
\hline Low status & 59 & 12.37 & 2.296 & 0.299 \\
\hline Moderate status & 141 & 13.26 & 2.271 & 0.143 \\
\hline High status & 200 & 14.06 & 2.868 & 0.34 \\
\hline Total & 400 & 13.43 & 2.409 & 0.123 \\
\hline \multicolumn{7}{|c|}{ ANOVA } \\
\hline \multicolumn{7}{|c|}{ Sum of f Squares } & Df & Mean Square & F & Sig. \\
\hline Between Groups & 35.06 & 2 & 17.53 & 3.054 & 0.048 \\
\hline Within Groups & 2186.898 & 397 & 5.74 & & \\
\hline Total & 2221.958 & 399 & & & \\
\hline
\end{tabular}

Table 4: Anova Descriptive Analysis for Tourism and Improved Social Status of the People of Cross River State $(\mathrm{N}=400)$

Source: Field Survey 2019

\begin{tabular}{|c|c|c|c|c|}
\hline (I)social status & (J) social status & Mean Difference (I-J) & Std. Error & Sig. \\
\hline \multirow{2}{*}{ Low status } & Moderate status & 0.109 & 0.346 & 0.753 \\
\cline { 2 - 5 } & High status & 0.683 & 0.422 & 0.106 \\
\hline \multirow{2}{*}{ Average status } & Low status & -0.109 & 0.346 & 753 \\
\cline { 2 - 5 } & High status & $-.793^{*}$ & 0.322 & 14 \\
\hline \multirow{2}{*}{ High status } & Low status & 0.683 & 0.422 & 0.106 \\
\cline { 2 - 5 } & Moderate status & $.793^{*}$ & 322 & 0.014 \\
\hline
\end{tabular}

Table 5: Schefee Post Hoc Multiple Comparisons for Improved Social Status

*. The Mean Difference Is Significant at the 0.05 Level

\begin{tabular}{|c|c|c|c|c|}
\hline Model & R & R Square & Adjusted R Square & Std. Error of the Estimate \\
\hline 1 & $.554^{\mathrm{a}}$ & 0.307 & 0.302 & 0.763 \\
\hline
\end{tabular}

Table 6: Model Summary for Linear Regression Analysis to Measure the Effect of

Tourism on Increased Educational Opportunities of the People of Cross River State $(\mathrm{N}=400)$

a. Predictors: (Constant), Expansion of Education Literacy, Shaping the Mental Attitude of the People, Experience Nature and culture 


\begin{tabular}{|c|c|c|c|c|c|c|}
\hline \multicolumn{2}{|c|}{ Model } & $\begin{array}{c}\text { Sum of } \\
\text { Squares }\end{array}$ & Df & $\begin{array}{c}\text { Mean } \\
\text { Square }\end{array}$ & F & Sig. \\
\hline \multirow{3}{*}{1} & Regression & 102.082 & 3 & 34.027 & 58.435 & $.000^{\mathrm{b}}$ \\
\cline { 2 - 7 } & Residual & 230.596 & 396 & 0.582 & & \\
\cline { 2 - 7 } & Total & 332.678 & 399 & & & \\
\hline
\end{tabular}

Table 7: Anova Showing Influence of Tourism on Increased Educational

Opportunities of the People of Cross River State $(\mathrm{N}=400)$

a. Dependent Variable: Tourism

b. Predictors: (Constant), Expansion of Education Literacy, Shaping the Mental

Attitude of the People, Experience Nature and Culture

\begin{tabular}{|c|c|c|c|c|c|c|}
\hline \multirow{2}{*}{\multicolumn{2}{|c|}{ Model }} & \multicolumn{2}{|c|}{$\begin{array}{l}\text { Unstandardized } \\
\text { Coefficients }\end{array}$} & $\begin{array}{c}\text { Standardized } \\
\text { Coefficients }\end{array}$ & \multirow[t]{2}{*}{$\bar{T}$} & \multirow[t]{2}{*}{ Sig. } \\
\hline & & $\mathrm{B}$ & Std. Error & Beta & & \\
\hline \multirow[t]{4}{*}{1} & (Constant) & 1.701 & 0.206 & & 8.255 & .087 \\
\hline & shaping the mental attitude of the people & 0.23 & 0.048 & 0.247 & 4.77 & 0 \\
\hline & experience nature and culture & 0.126 & 0.05 & 0.132 & 2.52 & 0.012 \\
\hline & expansion of education literacy & 0.249 & 0.047 & 0.282 & 5.254 & 0 \\
\hline
\end{tabular}

Table 8: Coefficients showing the Relationship between Tourism and Increased Educational

Opportunities of the People of Cross River State $(\mathrm{N}=400)$

a. Dependent Variable: Tourism

\subsection{Discussion of Findings}

\subsubsection{Tourism and Improved Social Status}

The first hypothesis examines tourism influence on improved social status of the people of Cross River State. The independent variable is Tourism while the dependent variable was improved social status. To test the hypothesis, one-way analysis of variance was used to determine the significant influence of tourism on improved social status of host communities. The dependent variable- social status was disaggregated into three level of measurement (low status, moderate status and high status). The result in the table above revealed that, there are three groups (low status, moderate status and high status); the calculated F ratio of 3.054 is statistically insignificant when compared with the critical F-ratio of 3.040 at 2, 381 degree of freedom. This mean that the null hypothesis which states that, there is no significant influence between tourism and improved social status of the people of Cross River State is still retained till a post hoc test is performed. It then follows that since there is no significant group difference a Post hoc test was performed to check were the difference lies. The difference among the group varies, social status as disaggregated, respondents of the opinion that tourism enhances low social status differ significantly from respondents with moderate status to tourism and improved social status ( $\mathrm{MD}=.109 ; \mathrm{p}<05)$; while respondents access to tourism benefits to their community with moderate status did not differ significantly with respondents who were of the view that tourism highly improves social status of host communities ( $\mathrm{MD}=-.793: \mathrm{p}>.05)$ similar result is seen between respondents with high status and low social status perception of their communities $(\mathrm{MD}=683 ; \mathrm{p}>\mathbf{0 5})$. From this result, there is a significant difference between respondents' opinion about tourism and improves social status of host communities, hence the result of the post hoc test was statistically significant.

The findings are in line with Ogorelc (2009), It enhances a common understanding and improves the social status of host community. De Kadt (1979) observed that, there are three types of interaction and contact between host community members and tourists. He observed that the first is the goods brought in by tourists and the services given by host community members, the second is the sharing of facilities between tourists and local residents while that last is the cultural exchange at the point of contact between tourist and local residents.

Local people are often motivated to promote tourism for the preservation of their cultural heritage and also promote social stability through the positive outcome from tourism potential on their economy. According to Archer, et al (2005), the differences in local identity and of cultural attitude toward tourists and individuals in the host communities are often seen as stimulants to mutual understanding between tourist and local residents. Archer, et al (2005) further reiterated that tourist aids in the preservation of historic relies or ancient culture. The social significance as well as benefits derived from tourism is that, tourism help host communities to maintain and sustain their traditional culture, increased intercultural communication and understanding, improved social welfare, quality of life, reciprocal culture and give and take, improved shopping and offer improved leisure opportunity. Secondly, for example, the people of Lao serve a remarkable tourism potential as a warm and kind people as an ethnic group that preserve her culture and way of life on ground of tourism. Through their cultural tourism practices, their locally manufacture handicrafts, especially textiles have attracted economic gain to the local people. They have a significant number of cultural artifacts ranging from archaeological, historic and religious sites that attracts visitor to the area. The socio-economic impact of tourism is multifaceted which deepen the cultural fabric of a society to sell their rich cultural heritage to fun seekers. Tourism has always 
been characterized as an industry consumes a significant number of resources in which a society relies on for survival. Tourists presences offers local residents financial or economic opportunity and brings a close attention of people in authority and regulated and preserved that which is cherished by all within the confines where such and be preserved and protected.

Many tourists often want to explore their tourism experience within areas of interest they mostly cherished such as hobbies, archaeological fines, cultural economic and economic benefit derived from such expeditions. "Roots" the visits of tourism to tourist sites and home of ancestry, a sense of community of tourist going back to their background to explore nature and taping from their natural resources serves good for the development of tourism. The above observation can be likened to religious tourism of sacred visitation of ancient places peculiar to their confession or adherence. Furthermore, tourist is often more concerned about their health and how they can and take long travels for vacation into new tourism sites and how they can frequent their visits annually. This is observable among older retirees who are adjudged to be wealthy to take on travel tourism or holiday vacation. At this point, most tourists have become more specialized and experienced in their expedition for more attractive tourist sites for vacation and relaxation in other to expect good services and experiences during their vacation. A host of business enterprises and business travelling or conferences at the international level are the bulk of tourism among older people.

Many tourists due to their wealth tourism experience are more considerate in their tourism expedition to account for the environment and social environment in which they seek to tour to be devoid of problem and terrorism. Due to their new trend of consideration, many older tourist sites are now being upgraded to meet the basic need of tourist expectations. In these happening, the sector currently employs modern technology such as videos, internets facilities Cinemas and other contemporary gazettes to meet the need of tourists. In Nigeria, there are various and multiples tourist attraction, but an enabling environment for tourists to explore has been a major challenge. This is often confronted by low participation, poor funding to improve sustainable development of host communities and other stake stakeholders in the tourism business in Nigeria.

These benefit that would have been derived socially from tourism could be inform of preservation and maintenance of traditional culture, improve and increased intercultural communication and understanding are all the benefits lacking from tourism in Nigeria as a country mostly cultural tourism. As a structural event, tourism is a social event which creates an enabling environment for fun seekers (Tsundoda et al, 2009).

The social relationship and interaction that occurs among tourists and local residents may affect tourist depending on the mode of reception of host community member to tourists which is often owed to the fact that most tourist may not be a breasted with the customs and tradition of the host residents. This effect may either be positive or most times negative depending on the situation experience by host residents (Mathieson et al, 1982). Through association and interaction with tourist, resident may learn newer thongs that can add values to their culture and lifestyle which in turn lead to development from the tourists' examples;

From this interaction, there may be improvement in lifestyles of the local people, behavioural modification and infrastructural development from the restructured facilities and usher in new educational opportunities such as scholarships, employment and income generation. Through this interaction there may be a significant improvement in other entertainment not formally taped as tourism potentials or activities such as entertainment, exhibitions etc. these will also improve other social events such as sports, like football competitions as well as dance competitions to add color to the period of event.;

Preservation and conservation of traditional cultural heritage which will promote significant cultural rebirth ancestral artifacts;

Through the visitation by tourist most unban tourist sites which may have been abandoned for a long time may also be revived by tourist interest in that area to enhance rural-urban migration or mobility. This urban revival and renewal on ground of tourism may in effect enhance job creation and sustainable development; create progrmmes that will go a long way to empower residents such as youths and women empowerment programmes and offer traveling opportunities globally to residents.

Visitation by tourists in all tourism destinations often bring about cultural rebirth and development. Visitations for cultural festivals in Nigerian have consistently increased to a higher percent of 30.3percent annually. It has been observed that such visitation by tourist's offers income enhancement opportunities to individuals generally as such visitation has never shown that the industry is detrimental to the socio-economic development of the country. Furthermore, the industry has been seen as a positive instigator to the improvement and development of internally generated revenue of any state tourist sites are located and visited by tourists as stakeholders like hotels, banks, individuals, as well as other private sector do yield up to 89 percent generated income for such states.

The impact of the tourism industry has significantly improved sustainable development of host communities through the provision of health centers, motorable roads, good hospitals as well as the provision of other necessary infrastructure for the host community members (Umana, 2010). In cross river state tourism has improve foreign earning as the state has in recent times experience foreign investors coming to the state to partner in many projects. This the sector has done by attracting investors to tourist centers or sites like The Tinapa or Obudu Cattle ranch at Obanleku and the Ugep international cultural festival in the State.

\subsubsection{Tourism and Increased Educational Opportunities in Cross River State}

The second hypothesis established the impact of Tourism on increased educational opportunities of the people of Cross River State. To test the hypothesis, linear regression was employed to test the degree of effect of micro finance credit 
scheme on house hold income. Furthermore, the dependent variable was disaggregated into three- expansion of education literacy, shaping the mental attitude of the people, experience nature and culture. From the Decision rule: if $\mathrm{P}$ value is greater than 0.05 accept $\mathrm{Ho}$ reject $\mathrm{H}_{1}$

Results of regression analysis carried out reveal a P value of 0.087 with $\mathrm{df}(4,400)$ and an $F$ value 58.435 . This further followed by the $t$-value of 8.255 as against the critical $t$-value of 3.723 to determine the independent influence of tourism in the promotion of enhanced educational opportunities to the host communities. Furthermore, since $\mathrm{P}$ value is less than 0.05 , thus we reject the null hypothesis and accept the alternate hypothesis. This implies that there is significant relationship between tourism and increased educational opportunities of the people Cross River State.

The findings are in line with Mocoamere, (2000), who reiterated that tourism also helps Improvement in education and literacy expansion and is one of the major impacts of the tourism industry. The sector shapes individuals' mental attitude through interaction with people from different linguistic background. Tourism as an industry has the potentials to offer economic opportunity as well as educational development to local resident who actively participate in the sector (Udeme, 2010).

Stakeholders in the tourism sector such as fashion design schools, colleges, food craft institute, and university departments, Hotel management institutes often undergo tourism related courses. It offers travels tour to educators and other people for adventures purposes as most people often travel in badges to explore the countries natural and manmade resources and site seeing such as landmarks, landscapes, cultural events museums amongst others in appreciation of nature and other art works. It also offers opportunities for educational art travels, research expeditions, and the discovery world of technology and cultural studies of ancient cities. All of these are the information basis of educational tours that tourism usually explores through their various researches which also offers professional development. These tours in world tourism include the entrepreneurial strata travelled to France which is a middle- class travel expedition, as well as the Britain and Germany travels expedition as a major technological goal of progressive innovations and industrialization. These middle-class educational travel expedition amongst this country is often aimed at promoting or the development of trade, improvement in agriculture, development of technology and the development of manufacturing industries through their direct contact with individuals involved. The entrepreneurial sector of the tourism industry improves foreign exchange income and also offers employers the opportunity to derive an efficient benefit to participating communities. It offers educational opportunities such as excursions to nomadic rural area of the world within a specify time for the advancement of knowledge which in turn improve income earnings to host communities. The tourism entrepreneurship has been the important major industry in Cross River State and it is rapidly growing in recent years. In cross river state of Nigeria, the sector has developed her entrepreneurial skill, as the state has nee adjudged as the tourist based of the nationNigeria with a clean environment. Through the influence of tourist activities in the state, the town has been a habitable place for tourist to inculcate their specialized skills to most of the participating residents to keep tourism activities alive.

This tourism entrepreneurial skill on local residents has made tourism activities efficient and satisfactory to tourist desired services. This impact has made other disadvantaged communities without tourism site to begin to explore in other to tap from their naturally abandoned tourism site and also get involved to other community's tourist activities during the period of event. This is owed to the fact that lack of participation of disadvantage groups may seem alienation and marginalization, hence the need for the active participation of other communities or the development of xenophobic tendencies. In most places where local residents have the needed skill for created works of art, there is usually an increased in capital generation through the direct patronage from tourists. Education ranks high on tourism development and promotion campaigns, tackling lawlessness and ignorance regarding the importance of tourism as well as encouraging the citizen's pride in the culture and the beauty of their land. (Mocoamere, 2000). The Chief of Human Resource Development, WTO, Fayos-Sala confirms that there is a lack of quality in tourism education and training worldwide because it does not correspond well to the needs of employers. To become competitive in tourism governments, have to realize that human capital is just as important as financial capital. So, by improving education, we can create more jobs and equip new groups joining the industry with skills Erdoardo in (World Tourism Organisation, 1998).

\subsubsection{Focus Group Discussion Analysis}

FGD interview was schedule with civil servants, farmers, politicians, students and traders who must have been affected with the various impact of tourism development. In order to conduct the FGD, the researcher and his research assistant conducted the interview starting with an introduction (introducing the topic under discussion and the aim of the research). The introduction was followed by the composition of the interview to include, a moderator, time keeper (research assistant), note taker with a recording phone, photographer and the selected participants: (10-12 participants).

\subsubsection{In-Depth Interview Analysis}

To present the in-depth interview result, the researcher contacted the secretary, council of chiefs; Yakurr Local Government area to examine the impact of lebuku festival as an aspect of cultural tourism on the socio-economic wellbeing of the people. Furthermore, the researcher interviewed the chairman Cross River State Tourism Board, to determine the extent to which the sector has contributed to sustainable development of the people of Cross River State. For ethical consideration of confidentiality, names of participants were not mentioned.

From the interview guideline provided for respondents or participants, respondents responded differently to each of the items with the follow-up probing questions. The researcher contacted the secretary, council of chiefs; Yakurr Local Government area to examine the impact of lebuku festival as an aspect of cultural tourism on income generation and sustainable development of the people which appears to be the first item in the interview guideline.

Comparison of Quantitative and Qualitative Analyses. 
From the foregoing, both analyses are responses from participants within the study area, who have direct impact on the contribution of tourism on the sustainable development of the people of Cross River State. Though it was observed that, there are variations in their individual opinion on the concept of tourism, the quantitative analysis has placed people's options as they responded to each item to be their opinions.

It was observed that, they are linked to qualitative responses as indicated in the guidelines thereby creating a harmonious consideration. The perception of the respondents on the variables under study from the qualitative view point seems reliable as the interaction was one on one with the participants. Here respondents spoke out their minds without fear or favor. But responses from the quantitative view point were lacking freedom of expression by participants due to limited or closed ended nature of the instrument.

Reactions and counter reactions from both analyses respondents centered on the relationship between variables under study with the majority carrying the upper hand claiming that, there is significant relationship as well as influence existing between the dependent sub variables that were identified from the major dependent variable namely; income generation; job creation; improved social status; increased educational opportunities and the independent variable being tourism. However, the two approaches were very useful in the study as they enabled the researcher to generate the relevant data for analysis.

\section{Summary, Conclusion and Recommendations}

\subsection{Summary}

The study examined the impact of Tourism on sustainable development of the people of Cross River State, Nigeria. The specific objectives were to determine the influence of tourism on improved social status and the relationship of tourism on increased educational opportunities. Relevant and related literatures were reviewed. The theory adopted was endogenous development model. The study adopted the survey design with the triangulation of qualitative (focus group discussion and in-depth interview) and quantitative approaches. The multi-stage sampling procedure was adopted. Data were obtained from 400 respondents derived through Taro Yamene's sample size determination formula.

Data sources were both primary and secondary. The obtained data were analyzed using simple percentages for socio demographic data, while the key variables were analyzed using ANOVA and linear regression respectively. The analysis revealed that:

- Tourism has a significant influence on improved social status of the people of Cross River State.

- Tourism has a significant relationship to increased educational opportunities of the people Cross River State.

\subsection{Conclusion}

From the result of this study, findings revealed that Tourism has a significant effect on sustainable development of the people of Cross River State, Nigeria. A critical review and appraisal on the study show a significant relationship between variables such as tourism and improved social statues, as well as tourism and enhanced educational opportunities to host communities.

It was further observed that a disparity exists between the general perception of tourism and the level of its practical influence on sustainable development of individuals mostly host communities and a partial concordance between developmental strides brought in by tourism for a sustainable infrastructural development of tourist sites. Hence, while the pattern of perception, belief, knowledge, income and acceptance shows a high need for government intervention for sustainable development of host communities, there is still no significant impact of tourism on human development either by the host community members or Cross River State generally.

From the study, it was observed that in spite of the high recognition of the state as the tourist base of the nation, the multiplier effect on individuals, and sustainable development is still in doubt as the state continues to fluctuate in her internally generated revenue, high rate of youth unemployment, youth restiveness, poor road network and poor manpower development. It is from this growing concern, the study suggestively recommends that an improvement on improved social status and increased educational opportunities ushered by tourism can significantly improve sustainable development of the people of Cross River State, Nigeria

\subsection{Recommendations}

Based on the findings, the following recommendations are made:

- Since tourism enhances a common understanding and improves the social status of host communities, recreational facilities should be created in those locations with tourism potentials to help bring about possible exchange of goods brought in by tourists; services rendered by the members of the host communities and contact between host community members and tourists. For effective improvement in the social status of host communities, there is need for the provision of health centers, motor-able roads, good hospitals as well as other necessary infrastructures for the host community members to enable them function and have a sense of belonging. This will serve as stimulants to mutual understanding between tourist and local residents and help in the preservation of historic relies or ancient culture. Furthermore since tourism industry has the capacity of helping host communities to maintain and sustain their traditional culture, increased intercultural communication and understanding, improved social welfare, quality of life, reciprocal culture of give and take, improved shopping and offer improved leisure opportunity, this industry should be expanded to those areas that are not blessed with natural tourism endowments. Since it has been observed that tourism improved social status of host communities, other Local Government Areas in the state should tap from their resource in other to discover tourism potentials 
taking example from the Ugep- (labuku cultural festival as an aspect of cultural tourism). If this is done it will in no small way improve their social status among committees of Local Government Areas.

- Since tourism also enhances improvement in education and literacy expansion as well as shapes individuals mental attitude through interaction with people from different linguistic background, there is need for stakeholders in the tourism sector to undergo tourism related courses in educational institutions for a considerable period of time to enable them gain knowledge and skill in fashion design, restaurants and hotel management and arts and crafts work. The sector has the potentials to offer economic as well as educational opportunities to local residents who actively participate in the sector. It offers travels tour to educators and other people for adventures purposes as most people often travel in badges to explore the countries natural and manmade resources and site seeing such as landmarks, landscapes, cultural events, museums amongst others in appreciation of nature and other art works. To become competitive in tourism, the government has to realize that human capital is just as important as financial capital. So, by improving educational opportunities, we can create more jobs and equip new groups joining the industry with skills. Lastly, tourism in the state should be incorporated in the school curriculum for more increased educational opportunities.

\section{References}

i. Archer, B., Cooper, C. \& Ruhanen, L. (2005). The Positive and Negative Impacts of Tourism. (In Theobald, W. ed. Global tourism. 3rded. New York: Elsevier.

ii. Bassand, M. Brugger, E.A. Bryden, J.M. Friedman, J. \& Stuckey, B. (1986) Self-Reliant Development in Europe Theory, Problems, Actions Gower, Brookfield, Vermont

iii. Dalat G (2010) Developing Rural Based Tourism as a Strategy for Rural Development in Nigeria; Int. J. Creativity Tech. Dev. 2:1-3.

iv. De Kadt. (1979). Tourism: Passport to Development. Third World Quarterly, 3, 340-343. http:/ / dx.doi.org/ 10.1177/ 003803857901300203

v. Ekwere, U. (2010). Exploring Potentials of Tourism for Economic Development:http:/ / w.w.w.nigerianbestforum.com/ blog/ ?p=42107

vi. Getz, D. and Smith, S. (1994). Festival and Event Tourism: Selected International Perspectives, Report Prepared for the Scottish tourists, Board, Calgary.

vii. Mathieson, A. \& Wall, G. (1982), "Tourism: economic, physical and social impacts", Longman: UK. Harlow.

viii. Mocoamere, V. (2000), "Taking Tourism to New Heights" Sowetan Wednesday September 6, 2000.

ix. OECD (1996) Networks for Rural Development Group of the Council on Rural Development OECD Paris

x. Ray, C. (2000) Endogenous Socio-Economic Development and Trustful Relationships: Partnerships, Social Capital and Individual Agency the Dialectic of Local Development: The Case of the EU LEADER 1 Rural Development Programme CRE Working Paper (45), University of Newcastle.

xi. Tsundoda, T. \& Mendlinger, S. (2009). Economic and Social Impact of Tourism on a Small Town: Peterborough New Hampshire. Journal of Service Science Managements, 2(2):61-70.

xii. Udeme E., (2010). Exploring the potential of tourism for economic development: Nigerian latest newspaper online $\mathrm{NBF}$ Retrieved http:// www.nigerianbestforum.com/ blog/ exploring-potential-of-tourism-for-economicdevelopment/ \#sthash.wWdCC9V2.dpuf

xiii. Umana, S.A. (2010). Tourism and Socio-Economic Development in Nigeria. Monograph. University of CalabarNigeria. Unpublished

xiv. Wall, G. \& Mathieson, A. (2006). Tourism: Change, Impacts and Opportunities, Harlow, England: Pearson Education Limited.

xv. World Tourism Organization, (1998), "Unleashing Tourism's Job Creation Potential” News from World Tourism Organization, Madrid (27/1/98). 